\title{
UM LUGAR PARA A REFERÊNCIA, SOB UM PONTO DE VISTA DA ENUNCIAÇÃO
}

\author{
ALENA CIULLA*
}

\begin{abstract}
RESUMO: Na esteira do questionamento que Benveniste provoca sobre a noção de arbitrariedade do signo saussuriano, abre-se a possibilidade de que se resgate a referência, fenômeno banido por Saussure pelo motivo de retornar à relação das palavras com as coisas. A partir de uma redefinição do signo, e de uma reflexão pautada por pressupostos enunciativos, sugeridos também por Benveniste, propomos, então, uma abordagem para a referência, conceituando-a como um fenômeno realizado na enunciação. Sob este ponto de vista, não se trata de uma cartografia da realidade do mundo, mas de um saber que se constitui na língua e não pode ser visto separadamente do homem que fala. Os objetos a que nos referimos são construtos, fruto das noções que os falantes formulam sobre eles, na língua e pela língua.
\end{abstract}

Palavras-chave: referência; enunciação; arbitrariedade do signo linguístico.

RESUMÉ: À la suite de l'interrogation que Benveniste déclenche sur la notion de l'arbitraire du signe saussurien, la possibilité de récupérer la référence, phénomène banni par Saussure pour revenir au rapport des mots aux choses, s'ouvre. A partir d'une redéfinition du signe, et d'une réflexion guidée par des présupposés énonciatives, également suggérées par Benveniste, nous proposons donc une approche de la référence, la conceptualisant comme un phénomène réalisé dans l'énonciation. De ce point de vue, il ne s'agit pas d'une cartographie de la réalité du monde, mais d'une connaissance qui se constitue dans la langue et ne peut pas être séparée de l'homme qui parle. Les objets auxquels nous nous référons sont des constructions, fruit des notions que les locuteurs formulent sur ces objets, dans la langue et par la langue.

Mots-clés: référence; énonciation; arbitraire du Signe Linguistique.

\section{INTRODUÇÃO}

Ainda que, para Saussure, a relação das palavras com as coisas escape à observação do linguista, não podemos negar que, ao falar, referimo-nos ao mundo. Por outro lado, sabemos, de acordo com Mondada e Dubois [2003] (1995) e Apothéloz (2001), que a resposta a essa questão também não está na lógica da Filosofia Analítica, pois a referência não é uma mera verificação de correspondência de palavras a objetos.

Como resgatar, então, este incontornável problema, para explicá-lo, de um ponto de vista linguístico? Neste artigo, nosso objetivo é o de sugerir uma

" Universidade Federal do Rio Grande do Sul (UFRGS), Porto Alegre, RS, Brasil. alenacs@ gmail.com 
abordagem sobre como nos referimos ao mundo, considerando que o fazemos na língua e partindo de certos pressupostos de como a língua funciona.

Para tanto, é preciso um arcabouço teórico que abarque, em primeiro lugar, um sistema linguístico, cuja arquitetura seja capaz de suportar a relação com as coisas do mundo, em toda a complexidade que implica a ideia de que essa relação não é um mero espelhamento das condições lógicas de verdade; em segundo lugar, que leve em conta a língua em uso. Por isso, neste trabalho, para dimensionar a referência, partimos de uma discussão sobre o signo linguístico e suas relações, tal como propõe Benveniste, e tecemos uma reflexão pautada por pressupostos enunciativos, sugeridos também pelo mesmo autor. Acreditamos que, nesse percurso, é possível realizar nosso intento, alinhavando bases que fundamentem uma teoria da referência, conceituando-a como um fenômeno realizado na enunciação, pelos falantes.

Iniciamos pela discussão de um texto intitulado $A$ natureza do signo linguístico, em que Benveniste [1939](2005) refere-se ao famoso exemplo de Saussure sobre o "boi", que consta no Curso de Linguística Geral $(C L G)^{1}$. O exemplo teria sido dado para reforçar a noção de arbitrariedade do signo e está contido no trecho que copiamos ${ }^{2}$, a seguir:

O laço que une o significante ao significado é arbitrário, ou então, visto que entendemos por signo o total resultante da associação de um significante com um significado, podemos dizer mais simplesmente: o signo linguístico é arbitrário.

Assim a ideia de "soeur" ("irmã") não está ligada por nenhuma relação interior à sequência de sons $s-\ddot{o}-r$ que lhe serve de significante; poderia ser representada igualmente bem por outra sequência, não importa qual; como prova, temos as diferenças entre as línguas e a própria existência de línguas diferentes: o significado "boeuf" ("boi") tem por significante $b$-ö-f $f$ de um lado da fronteira franco-germânica, e $o-k-s$ (Ochs) do outro. (SAUSSURE, 1975, p.81-82)

Porém, ao sugerir que boeuf e Ochs se referem a um mesmo conceito, Saussure estaria considerando as coisas do mundo, excluídas anteriormente (por Saussure mesmo) da definição de signo. Além disso, o conceito "boi" parece ser o mesmo para os dois casos "dos dois lados da fronteira", o que faz pensar num conceito a priori de boi, que é justamente outra ideia fundamental que, supomos, Saussure também refuta.

A raiz do problema, neste exemplo do "boi", para Benveniste [1939](2005), está na noção de arbitrariedade do signo postulada por Saussure. E é por este viés que desenvolve seu raciocínio.

${ }^{1}$ Tratamos, aqui, apenas do $C L G$, visto que esta é a fonte de Benveniste para o questionamento sobre a natureza do signo linguístico. No entanto, estamos cientes da discussão em torno desta problemática, a partir da recente filologia saussuriana, envolvendo diversas outras fontes, em especial os manuscritos de Saussure.

${ }^{2}$ Observamos que, embora a citação seja a da edição brasileira, foram feitas algumas alterações no texto da tradução, com o intuito de manter uma maior proximidade com o original, em francês. Os dois trechos em que apresentamos uma alternativa de tradução são 1) onde há "mar" na edição brasileira, preferimos manter "soeur", conforme o original; 2) mantivemos "o significado 'boeuf' tem por significante $b-\ddot{o}-f$ ", já que no original, em francês, aparece: "le signifié « boeuf » a pour signifiant b - ö - f "(CLG, 1975, p.100); na edição brasileira, para este trecho, aparece: "o significado da palavra francesa boeuf ("boi") tem por significante b-ö-f”(CLG, 1975, p.82). 
Os questionamentos de exemplos, somados às várias controvérsias relacionadas à compilação do CLG e ao fato de que a arbitrariedade do signo é um tema fundamental em Saussure (conforme NORMAND, 1973, a arbitrariedade do signo é considerada como o conceito saussuriano por excelência), provocaram uma ampla discussão e um grande número de publicações, por diversos outros autores, como Engler (1962), Normand (1973), Milner (1975), De Mauro (1976), Gadet (1987), Jakobson (1992) e Bouquet (1997).

Essa inquisição sobre a formulação de Saussure promoveu, então, tanto um aprofundamento do estudo do legado do mestre quanto um ponto de partida, de que alguns autores se valeram para desenvolver conceitos e abordagens próprias, muitas vezes, afastando-se da abordagem proposta no CLG ou ampliando-a. Parece-nos que Benveniste foi um desses autores, de acordo, também com Flores (2017):

No caso específico de Benveniste, pode-se dizer que a noção saussuriana de signo é um ponto de partida (o aspecto fundador da visada saussuriana), mas não um ponto de chegada de sua teorização (o aspecto prospectivo da teoria do genebrino). Assim, quer-se defender - e isso é uma hipótese - que a teoria da linguagem de Benveniste, no que diz respeito especificamente à noção de signo, inclui a teoria saussuriana ao mesmo tempo em que propõe algo que não cabe nela, que vai além dela. (FLORES, 2017)

De nossa parte, não nos compete, aqui, retomar uma avaliação, no intuito de discutir os méritos das críticas a Saussure e ao CLG, nem encontrar o fio de pensamento de Saussure, nem, tampouco, acusá-lo - ou aos compiladores do CLG, de uma incoerência.

Nosso interesse está no deslize que o exemplo do "boi" provoca, tal como é lido por Benveniste, ao retornar à questão da relação da língua com as coisas do mundo. E, consequentemente, na crítica de Benveniste [1939](2005) a Saussure (1975) que, a partir do que está posto no CLG, proporciona um aprofundamento do estudo sobre o arbitrário do signo linguístico e promove um deslocamento desta noção, redefinindo o signo.

Salientamos também que não se trata, aqui, de reavivar a antiga discussão sobre se a relação entre palavras e coisas é natural ou convencional, e, sim, de propor uma reflexão sobre o que possibilita, na língua e via língua, esta relação. Pois, assim, tratando do modo como, sob o pretexto do exemplo do "boi", o questionamento sobre a noção de arbitrariedade do signo é conduzido em Benveniste [1939](2005), é que vislumbramos a possibilidade de reencontrar o lugar a referência na discussão.

Além disso, acreditamos que a reflexão, como a que promovemos aqui, sobre os pilares que edificam a teoria sobre o funcionamento da referência na língua pode ser muito frutífero para o desenvolvimento de outras pesquisas nesta área. ${ }^{3}$

\footnotetext{
${ }^{3} \mathrm{~A}$ presente discussão se insere em um projeto de pesquisa, coordenado pela autora deste artigo e registrado sob o $n^{\circ} 32484$, intitulado "A referência - uma perspectiva a partir de Benveniste". Neste projeto, antevemos, ainda, também as consequências para as questões do texto que a discussão sobre a referência pode trazer, considerando, entre outros aspectos, que os processos dêiticos e anafóricos desempenham papel fundamental para a estrutura e coerência textual.
} 


\title{
2. O DESLOCAMENTO DA NOÇÃO DE SIGNO LINGUÍSTICO
}

\subsection{Primeiro movimento: da arbitrariedade para a necessidade}

Para articular seu raciocínio, Benveniste [1939]2005 parte da noção de signo, em conformidade com Saussure: o signo linguístico une um conceito [significado] e uma imagem acústica [significante] e são indissociáveis porque

\begin{abstract}
...nosso pensamento não passa de uma massa amorfa e indistinta. Filósofos e linguistas concordaram sempre em reconhecer que, sem o recurso dos signos, seríamos incapazes de distinguir duas ideias de modo claro e constante. Tomado em si mesmo, o pensamento é como uma nebulosa, em que nada é necessariamente delimitado. Não existem ideias preestabelecidas, e nada é distinto antes do aparecimento da língua (SAUSSURE, 1974 p.130).
\end{abstract}

A indissociabilidade do signo é também explicada pela famosa metáfora saussuriana da folha de papel: em uma face, estaria o pensamento e, no verso, o som: recortando-se o pensamento, estaríamos recortando, juntamente, o som. Da mesma maneira, na língua, não se pode isolar o pensamento ou a forma sonora que lhe é correspondente (a não ser, para este último, em um estudo de fonologia pura).

Entretanto, o problema surge, quando Saussure afirma que "o significante é imotivado, isto é, arbitrário em relação ao significado, com o qual não tem nenhum laço natural na realidade" (SAUSSURE, p.81). Para Saussure, então, o conceito de "soeur" não tem qualquer ligação com a sequência de sons $s-\ddot{o}-r$ que lhe serve de significante, sendo que qualquer outra sequência sonora serviria igualmente bem para compor este signo e, por isso, esta ligação é arbitrária.

Ora, se significante e significado são indissociáveis para a composição de um signo, o laço que os une não pode ser arbitrário, nem imotivado, mas, de acordo com Benveniste [1939](2005), necessário. Para defender esta afirmação, o autor argumenta:

O conceito ("significado") "boi" é forçosamente idêntico na minha consciência ao conjunto fônico ("significante") boi. Como poderia ser diferente? Juntos os dois foram impressos no meu espírito, juntos evocam-se mutuamente em qualquer circunstância. Há entre os dois uma simbiose tão estreita que o conceito "boi" é como que a alma da imagem acústica boi. O espírito não contém formas vazias, conceitos não nomeados.” (BENVENISTE, [1939]2005, p. 55-56)

É com base na questão enfatizada por Saussure de que o pensamento é indistinto antes do aparecimento da língua e, inversamente, também só é acolhida uma forma sonora que corresponda a uma representação identificável, ou seja, pela própria natureza indissociável entre significante e significado, que Benveniste se autoriza a afirmar que, então, a relação interna do signo não é arbitrária, mas é necessária. Sem a correspondência simultânea - um não vem antes do outro -, indissociável, entre significante e significado, o signo não existe.

Afirmar da necessidade, em vez da arbitrariedade, na relação entre significante e significado, é o primeiro passo do importante movimento que, entendemos, Benveniste articula, nessa questão. Mas ela não se encerra aqui. 


\subsection{Segundo movimento: do universal e do contingente}

Um outro aspecto, ainda, é apontado por Benveniste, no que poderia, à primeira vista, ser considerado como uma falta de rigor do raciocínio saussuriano:

Saussure cansou-se de dizer que a ideia de 'soeur' não está ligada ao significante $s-\ddot{o}-r$; porém não pensa menos na realidade da noção. Quando fala da diferença entre b-ö-f e o-k-s, refere-se contra a vontade, ao fato de que esses dois termos se aplicam à mesma realidade. (BENVENISTE, [1939]2005, p.54)

Benveniste salienta, neste trecho, o falseamento do pensamento de Saussure, ao evocar os conceitos "soeur" e "boeuf" como objetos da realidade do mundo, o que se opõe frontalmente à noção de que a língua é forma, não substância princípio conhecido, firmemente defendido por Saussure.

Os "verdadeiros" motivos pelos quais o raciocínio do mestre genebrino parece inconsistente aos olhos de Benveniste, como já mencionado, não nos compete, aqui, especular. Contudo, muito nos interessa desenvolver a reflexão que subjaz a uma das questões que emerge dessa discussão: o que, então, explica as diferenças entre as línguas e seus diferentes signos?

Por isso, reportamo-nos novamente ao texto de Benveniste, para assinalar que o autor, na verdade, não atribui o raciocínio aparentemente incongruente do exemplo do "boi" a um afrouxamento da atenção crítica de Saussure:

Eu veria, antes, aí, um traço distintivo do pensamento histórico relativista do fim do século XIX, um processo habitual a essa forma de reflexão filosófica que é a inteligência comparativa. Observam-se nos diferentes povos as reações suscitadas por um mesmo fenômeno: a infinita diversidade das atitudes e dos julgamentos leva à consideração de que nada aparentemente é necessário. Da universal dessemelhança, chega-se à universal contingência. A concepção saussuriana está ainda solidária, em certa medida, com esse sistema de pensamento. (BENVENISTE, [1939]2005, p.55)

Vê-se, neste ponto, o prenúncio de um novo deslocamento, que julgamos importantíssimo, da noção de universal e contingente, na proposta de Benveniste. Para entendê-lo, é preciso acompanhar a ilustração que o autor faz, a seguir, ao seu raciocínio, usando de uma comparação, em que definir o signo linguístico como arbitrário, porque um mesmo animal se chama boeuf num país e Ochs em outro, equivaleria a dizer que a noção de luto é arbitrária, porque para essa noção, na Europa, o símbolo é o preto, e na China, o símbolo é o branco. Para o autor, essa relação seria

Arbitrária, sim, mas somente sob o olhar impassível de Sirius ou para aquele que se limita a comprovar, de fora, a ligação estabelecida entre uma realidade objetiva e um comportamento

${ }^{4}$ Vale ressaltar, sobre esse trecho, que a hipótese levantada por Benveniste é reforçada por Normand (1973), quando a autora observa que Saussure ainda vivia a influência da filosofia e do modo de ver de seus contemporâneos e antecessores. Essa influência pode ser detectada não somente por hesitações, que muitas vezes dificultam seguir uma linha teórica coerente, mas também por termos empregados por Saussure, tais como verdade, evidencia, descoberta, que, também, de acordo com a autora, são indícios de que o terreno filosófico tradicional não havia sido totalmente abandonado. 
humano e se condena, assim, a não ver aí senão contingência. É claro que, com relação a uma mesma realidade, todas as denominações têm igual valor, o fato de que existem é, pois, a prova de que nenhuma delas pode pretender o absoluto da denominação em si. (BENVENISTE, [1939]2005, p.55).

E aqui se revela, parcialmente, o pensamento de Benveniste sobre essa questão: o universal não diz respeito ao fato de que haja uma única realidade objetiva e as diversas denominações sejam apenas contingências de um valor absoluto. Mas, muito diferentemente disso, o que está em jogo são os diferentes conceitos sobre as coisas, que as diferentes línguas e os diferentes falantes manifestam. Então, não é nem uma mera questão de "diversas denominações", como menciona Benveniste, pois não se trata apenas de diferentes nomes para as coisas, e, sim, de diversos modos de conceituar as coisas, o que se reflete e é reflexo dos diferentes falantes, das diferentes línguas e das visões de mundo que estão nelas contidas - e isso é que é universal. E por ser uma questão de diferentes modos de ver o mundo, todos tem igual validade, pois não se pode distinguir um como mais verdadeiro do que o outro.

É a partir desse segundo deslocamento que Benveniste assume que se pode falar em arbitrário. Para o autor, "O que é arbitrário é que um signo, mas não outro, se aplica a determinado elemento da realidade, mas não a outro. Nesse sentido, e somente nesse sentido, é permitido falar em contingência" (BENVENISTE, [1939](2005), p.56).

É colocado, assim, em xeque, o princípio da arbitrariedade do signo em Saussure (1974). Além de demonstrar que a relação interna do signo, entre significante e significado, não é arbitrária, Benveniste propõe também um outro modo de pensar a arbitrariedade, em um outro escopo para o que seja universal e contingente.

\subsection{Terceiro movimento: da mutabilidade e imutabilidade do signo}

Quanto à mutabilidade e imutabilidade do signo, tais princípios foram admiravelmente explicados por Saussure, elogia Benveniste [1939](2005): o signo é imutável, por um lado, porque é arbitrário, isto é, não existe um laço natural com a realidade; e é mutável, por outro lado, pois suscetível de mudança. Benveniste recupera esses princípios, mas observa que

Não é entre o significante e o significado que a relação ao mesmo tempo se modifica e permanece imutável, é entre o signo e o objeto; é em outras palavras, a motivação objetiva da designação, submetida, como tal, à ação de diversos fatores históricos. O que Saussure demonstra permanece verdadeiro, mas a respeito da significaçãos ${ }^{5}$, não do signo (BENVENISTE, [1939]2005, p.58).

Naturalmente que, se a relação de arbitrariedade não se dá entre significante e significado, mas entre signo e objeto, é entre este último par que se aplicam também os princípios de mutabilidade e imutabilidade. Reiteramos, no entanto,

${ }^{5}$ Atentamos para o fato de que Benveniste, aqui, usa o termo "significação", em itálico, para se referir à relação entre o signo e o objeto e distingui-la da relação interna do signo. 
que quando Benveniste afirma da arbitrariedade do signo, o faz em pelo menos duas maneiras diferentes do que fizera Saussure: em primeiro lugar, não se trata da relação significado-significante, mas da relação signo-objeto; em segundo lugar, não se trata de um arbitrário em relação a um universal absoluto do qual derivam contingências, mas de um universal que só pode ser concebido pela contingência.

E, com a atribuição do princípio da arbitrariedade à relação do signo com o objeto, é (re)admitido o mundo na relação com a língua.

Sobre o trecho citado nesta seção, ainda se faz necessário adotar, desde já, um posicionamento no que tange a um aspecto teórico importante que suscita o termo designação. Em Benveniste, no contexto do trecho citado acima, em que é enfatizada a relação entre o signo e o objeto, o leitor desavisado poderia pensar que designação é intercambiável por referência. Contudo, ao mencionar a motivação objetiva da designação, supomos que, para Benveniste, há outra motivação da designação: a do signo tomado em si.

Consoante esse raciocínio, em trabalhos anteriores sobre referência, como em Ciulla (2008), vimos considerando designação e referência como processos interligados, em que a designação, embora implique o apontamento a um objeto, está também associada ao processo específico de nomeação - o qual, por sua vez, diz respeito à relação interna de constituição do signo, qual seja, a de associar um significante a um significado. Já a referência é considerada como o fenômeno que diz respeito ao processo geral de apontamento para os objetos, no discurso, e não ao de nomeá-los.

Afirmamos, então, que a designação faz parte do ato de referenciar e pode se constituir como um modo de apontamento, já que revela a escolha do signo que é associado a um determinado objeto. E é nesse sentido que o termo designação será empregado neste trabalho.

Na seção 4.2 deste artigo, em que tratamos da relação entre referência e sentido, retomamos, brevemente esta questão, que, no entanto, merece ser mais extensamente discutida em trabalhos futuros.

\subsection{Quarto movimento: o valor, como dependente da necessidade}

Outro ponto discutido por Benveniste [1939](2005) que é crucial para a definição do signo e, especialmente, para a relação entre signo e objeto, é sobre o valor. E apela, mais uma vez, ao pensamento de Saussure, citando o seguinte trecho:

A escolha que chama determinado corte acústico para determinada ideia é perfeitamente arbitrária. Se não o fosse, a noção de valor perderia algo do seu caráter, pois conteria um elemento imposto de fora. De fato os valores permanecem inteiramente relativos, e eis aí o motivo pelo qual o elo entre a ideia e o som é radicalmente arbitrário (SAUSSURE, 1975, p.163)

Em primeiro lugar, sobre esse trecho, Benveniste [1939](2005) reitera sua discordância da questão da arbitrariedade da relação significante-significado: para o autor, a escolha que chama um corte acústico para uma ideia não é perfeitamente arbitrária - ela nem é arbitrária, aliás, pois é necessária. Um corte acústico sem 
correspondência com um conceito é apenas um som indistinguível e não significa coisa alguma na língua. Além disso, o que Benveniste identifica, nessa passagem do CLG, seria uma confusão entre ideia e o objeto real. E a prova desse engano é flagrada na afirmação do mestre genebrino de que a noção de valor ficaria corrompida, se contivesse um elemento de fora - expressão que Benveniste coloca em destaque, para salientar o lapso.

Para Benveniste, o valor permanece mesmo relativo - mas, aqui, novamente é preciso deslocar a noção: se o signo tomado em si não é arbitrário, o caráter relativo do valor não está ligado à arbitrariedade do signo. E, como o signo tomado em si não está em relação com a realidade, também o valor não poderia ser relativo à realidade - o valor é um atributo da forma, não da substância. Trata-se, portanto, de uma relação do sistema: os valores são relativos, então, uns em relação aos outros. E, por se definirem sempre em oposição (um signo é aquilo que os outros não são), "conservam-se em mútua relação de necessidade" (BENVENISTE, [1939]2005, p.59). Benveniste endossa, nessa passagem, mais uma vez, o caráter necessário do signo.

E, para a nossa pesquisa, é importante notar que não é o objeto real o entrave, para que se configure uma teoria consistente sobre o signo linguístico, mas de precisar como as relações no sistema se organizam de modo a permitir que haja referência ao real.

Vemos que, nessa reflexão, partindo da noção de arbitrariedade, somos convocados por Benveniste a redefinir o signo linguístico. E mais do que isso, seus apontamentos configuram-se como o alicerce de toda uma teoria que, tornando mais precisas as relações do signo, permite ir além daquilo que propôs Saussure, inclusive para tratar de assuntos, como os que podem fundamentar uma teoria sobre a referência.

Seguimos, então, na rota proposta, para tratar de alguns desses assuntos fundamentais, a começar pelas implicações dos deslocamentos sugeridos até aqui por Benveniste, em especial o que diz respeito à arbitrariedade do signo em relação às coisas do mundo.

\section{ESPECULAÇÕES A PARTIR DA NOÇÃO DE CONTINGÊNCIA: AS DIFERENTES LÍNGUAS}

O que apresentaremos neste ponto não se trata de definições ou afirmações efetivamente realizadas por Benveniste, mas de formulações que se pode derivar de sua obra, em que repensamos as implicações do deslocamento da noção de arbitrariedade e contingência do signo para uma teoria da referência.

Refllitamos, inicialmente, sobre o aspecto de contingência que está relacionado à existência de diferentes línguas. Os falantes se apropriam de um determinado conjunto de sons para constituir os sons de uma língua: entre todos os que o ser humano consegue emitir, cada língua delimita o seu conjunto - e isso é contingente. E, ao se deparar um com o outro e com as coisas que reconhecem 
no mundo, os falantes se referem a essas coisas, por serem dotados de faculdade simbólica, pela possibilidade da linguagem.

Defendemos a ideia de que, segundo Benveniste [1939](2005), não há uma associação natural entre designação e coisa designada, nem entre o nome que se dá, nem entre o conceito que se forma. Por isso, na relação do signo com o objeto, há também contingência. Contudo, quando um signo emerge, não podemos mais dizer que qualquer sequência de sons serviria, pois justamente o que possibilita evocar um signo é a associação de determinado significante com determinado significado. Por isso, o signo, na sua relação interna, é necessário. E quais são, então, as implicações dessas relações de contingência e necessidade do signo, para uma teoria da referência?

Desenvolvendo a ideia de necessidade do signo, podemos dizer que, ao mudar o significante, isso implica também na alteração do significado, conforme a metáfora da folha de papel; não se trata, então, de chamar a "mesma coisa" por outro nome (sob o olhar impassível de Sirius...).

Um ponto delicado que é preciso salientar, antes de seguir adiante, é a possível confusão entre objeto e conceito (de que conforme BENVENISTE, [1939]2005, Saussure teria sido vítima). Ora, referir-se a um objeto é falar do mundo, e não falar o mundo. Em outras palavras, um conceito não é um objeto, mas algo que se diz dele - entendido, aqui, que, se existe um conceito, existe um modo de referi-lo na língua. Daí que um mesmo objeto do mundo é percebido pelos falantes, que a ele atribuem e discretizam diferentes conceitos - aos quais invariavelmente estão associadas diferentes modos de referi-lo.

Retornando ao exemplo que deu origem a todas essas reflexões, acreditamos, então, que somente boeuf está associado ao conceito "boeuf" e Ochs ao conceito "ochs", que - aqui é que Saussure teria se perdido - não são a mesma coisa. O modo de falar particular de cada língua e particular de cada indivíduo faz com que os signos sejam diversos - ou melhor, representam a diversidade do modo de ver o mundo (pelos diferentes falantes, diferentes culturas, pelas diferentes línguas etc). Assim, "boeuf" e "ochs" não se referem à mesma realidade, pois os falantes não percebem esta coisa do mundo exatamente do mesmo jeito.

$\mathrm{O}$ falante comum explica a relação entre língua e realidade de maneira apenas intuitiva. Para ele, há total adequação entre o signo e o objeto, pois "o signo encobre e comanda a realidade; ele é essa realidade" (BENVENISTE, [1939]2005, p.57). Assim, conceito e a própria coisa conceituada se confundem. O nome das coisas, todos concordam que muda, pois especialmente entre línguas diferentes, isso é bastante evidente; mas ao nos depararmos com um objeto como 'boi' ou "irmã", podemos ter a ilusão de que se trata sempre de um mesmo conceito, independentemente da língua ou do modo como a ele nos referirmos. $\mathrm{Na}$ dependência de uma concepção assim intuitiva, o falante não se dá conta de que os conceitos sobre as coisas não são os mesmos, de língua para língua e mesmo de indivíduo para indivíduo, e que o diferente modo de designá-los é uma consequência disso. Esse diferente modo de designação é consequência e é determinante do conceito que se tem, ao mesmo tempo. Para o falante comum, parece que o elemento vem antes, mas, na verdade, é o sistema que o determina. 
E é esse raciocínio que permite falar de referência sem retornar à questão da "verdade do mundo" ou ao que seria externo à língua. Do ponto de vista linguístico, representamos - apenas e sempre - modos de ver o mundo, limitados, em parte, por aquilo que o sistema da língua nos permite dizer/perceber.

A grande diversidade de atitudes e julgamentos não se dá por serem essas diversas atitudes e julgamentos derivações de um conceito único, como mencionamos anteriormente, mas por serem produto de diferentes formulações sobre o mundo.

Todavia, detemo-nos, ainda que brevemente, sobre a ideia de que o sistema determina os conceitos da língua, que remete à célebre discussão sobre o determinismo linguístico, levantada por Boas, Humboldt e Whorf, mencionada por Slobin (1996). De maneira bastante resumida e salientando o aspecto que nos interessa mais de perto, neste artigo, podemos dizer que a ideia principal envolvida aí e compartilhada por Boas (1966) é a de que as estruturas semânticas, diferentes entre as diferentes línguas, refletem-se na forma de pensar e agir do falante de cada língua. Dessa maneira, linguagem, pensamento e cultura estão profundamente conectados, podendo-se concluir que cada língua possui uma visão de mundo distinta. Contudo, conforme aponta Slobin (1996) a versão do determinismo linguístico defendida por Humboldt (1836) e Whorf (1956) não é exatamente a de Boas (1966), pois, enquanto para esses autores os conceitos não têm existência sem a linguagem, Boas sugere que há um "conceito completo", que existiria na mente na forma de uma "imagem mental". Slobin (1996) posiciona-se, nesta questão, mais de acordo com Humboldt e Whorf e afirma que as línguas não são sistemas neutros de codificação de uma realidade objetiva, mas cada uma constitui uma orientação subjetiva sobre o mundo de experiências humanas. Parece-nos que esse modo de perceber a questão de Slobin (1996) vai ao encontro do pensamento de Benveniste também, para a questão dessas diferentes maneiras de perceber o mundo entre as diferentes línguas: de um lado, há uma certa imposição da própria língua para aquilo que os falantes conseguem significar; por outro, há sempre a possibilidade de ressignificar o mundo (dada, especialmente, pelas condições de enunciação, como veremos no item 4), seja em uma mesma língua, seja entre línguas diferentes.

Assim, ainda que os seres humanos sejam todos dotados, em princípio, de uma capacidade para a linguagem, um indivíduo aprende a língua que é falada no lugar em que ele nasce e cresce e, com os recursos de que essa língua dispõe, categoriza o mundo de acordo com esse ponto de vista, o da sua língua, que envolve aspectos da sua cultura, do seu tempo, do seu conhecimento e experiência particular. Sob esse ponto de vista, não existe um conteúdo universal absoluto por isso não se pode afirmar da validade de um conceito em detrimento de outro: são modos de ver o mundo. E o universal emerge dessas contingentes e diferentes visões de mundo.

Explicitamos, acima, as implicações da noção de contingência do signo para a referência. Entretanto, faz-se necessário, ainda, reforçar um ponto importante, que diz respeito à ideia de que signo não é sinônimo de substantivo e nem de palavra. 
Neste trabalho, ocupamo-nos principalmente de discutir signos, como o que o significante "boi", em um enunciado, pode evocar ao associar-se com um conceito "boi". No entanto, não nos restringimos à palavra como equivalente a signo. De acordo com Saussure, uma unidade concreta de signo é incompatível com a noção de palavra. Um significante, como o representado pelo símbolo fonético /s/, em português, pode ser associado ao conceito "plural", por exemplo, em certos contextos, formando um signo. No CLG (SAUSSURE, 1975, p.122), além das desinências nominais, também são mencionados os sufixos, prefixos e radicais, como exemplos de unidades concretas (de signos). O exemplo dado é o sufixo derivacional -oso em desejoso ou em desditoso. Assim, a sequência sonoro - oso, estando associada ao conceito de força, abundância ou à simples derivação de qualidade, configura-se como um signo em língua portuguesa. O princípio geral é o de que falamos não por signos isolados, portanto, mas por grupos de signos, "massas organizadas" (conforme SAUSSURE, 1975, p. 148), que são elas próprias signos. E é nesse contexto de funcionamento que consideramos "boi" ou “irmã”. Conforme o CLG:

Em resumo, a língua não se apresenta como um conjunto de signos delimitados de antemão, dos quais bastasse estudar as significações e a disposição; é uma massa indistinta na qual só a atenção e o hábito podem nos fazer encontrar os elementos particulares. A unidade não tem nenhum caráter fônico especial e a única definição que dela se pode dar é a seguinte: uma porção de sonoridade que, com exclusão do que precede e do que segue na cadeia falada, é significante de um conceito. (SAUSSURE, 1975, p.120)

O conceito a que se associa um significante, portanto, não diz respeito apenas a conceitos expressos por substantivos ou palavras, mas por qualquer segmento fônico a que se atribua algum significado na língua e se configure como uma unidade.

Na sequência da proposta deste trabalho, apresentamos os fundamentos para repensar o lugar da referência como um processo enunciativo.

\section{REFERÊNCIA E ENUNCIAÇÃO}

\subsection{O aparelho formal da enunciação}

Como vimos, há uma relação necessária entre significante e significado, que é interna ao signo. Em outra relação está o signo com o mundo: ela é contingente, pois que há diferentes modos de conceituar objetos - o que revela a diversidade de modos de ver o mundo. Porém, essa relação do signo com o mundo não é “externa", como se poderia supor, à primeira vista.

Como mencionamos na introdução deste artigo, não podemos nos fundamentar em uma noção de língua que exclua o mundo, pois não há como negar que a ele nos referimos, quando falamos; entretanto, para incluir o mundo, precisamos de uma teoria que dê conta de explicar como fazemos isso, ou seja, de explicar o que fazemos do ponto de vista linguístico quando falamos e nos referimos ao mundo. 
A redefinição da natureza do signo linguístico, conforme demonstramos antes, abre a possibilidade da reflexão sobre a referência, mas não a explica. Para tanto, encontramos, seguindo sugestão de Flores (2013), em diversos textos, mais especialmente em Benveniste [1956][1958][1959]2005 e [1965][1966] [1970]2006, uma importante teorização que converge numa explicação sobre a língua em funcionamento - que é quando se dá a referência e, por isso, o nosso interesse.

Salientamos que Benveniste não se dedicou largamente ao tema referência. Mas lançou bases, para que uma sólida teoria sobre o assunto seja constituída. Nas palavras de Flores (2017):

\begin{abstract}
A concepção de signo em Benveniste não é binária; ela inclui um terceiro elemento. Em Benveniste, o signo é uma série de três termos. E que fique bem claro: não se está defendendo que o terceiro termo em Benveniste é o referente, o objeto no mundo, tal como se encontraria concebido no campo da lógica, mas a referência, o que é coisa muito diferente, uma vez que a referência, em Benveniste, não advém da realidade no mundo, mas de uma realidade de discurso. Aliás, o tipo de referência - se "constante" e "objetiva", de um lado, ou "vazia", apta a se tornar "plena", de outro lado, é um aspecto distintivo que se localiza no interior do sistema de valores que definem o signo. Não é algo que se acrescenta ao sistema. A série de três termos, portanto, está pensada por Benveniste no sistema de valores concebido por Saussure. (FLORES,2017)
\end{abstract}

Flores toca em pontos importantíssimos, como, em primeiro lugar, o fato de que, para a abordagem de Benveniste, a coisa significada não é "extralinguística", pois que é significada no discurso; a realidade é a do discurso. Em segundo lugar, no fato de que a concepção de signo de Benveniste prevê a relação do sistema que permite explicar como a referência atua, criando essa realidade de discurso.

Voltamos ao texto do autor, para compreender, primeiramente, como ele define enunciação. Em $O$ aparelho formal da enunciação, Benveniste distingue entre o "emprego das formas" e o "emprego da língua". O primeiro estaria relacionado às regras sintáticas da língua, articuladas, por sua vez, a "regras de formação", na terminologia do autor, as quais se referem às variações morfológicas e combinatórias dos signos. Sendo essas articulações limitadas entre si, teoricamente, é possível fazer um inventário exaustivo, tanto de formas, como dos empregos. Já as condições de emprego da língua são outras, pois se trata da própria língua em funcionamento. A enunciação consiste justamente em "colocar em funcionamento a língua por um ato individual de utilização". (BENVENISTE, [1970]2006, p.82)

E, neste ato individual, o locutor aparece como o principal parâmetro para as condições necessárias da enunciação. Em primeiro lugar, porque "antes da enunciação, a língua não é senão possibilidade de língua". Em segundo lugar, porque, ao enunciar e se apropriar da língua, a própria presença do locutor na sua enunciação "faz com que cada instância do discurso constitua um centro de referência interno". (BENVENISTE, [1970]2006, p.84).

Este centro de referência interno, vale lembrar, inclui as coordenadas marcadas pelo aqui e agora, que delimitam, respectivamente, as instâncias espaciais e temporais do discurso que contém o eu. 
Outro ponto fundamental é o de que sempre que o locutor assume a língua e o centro da enunciação, ao mesmo tempo, ele institui o outro diante de si, quer reconheça ou não a presença deste outro. Isto é, toda enunciação postula um alocutário.

Como a última das condições de enunciação, o autor afirma:

A língua se acha empregada para a expressão de uma certa relação com o mundo. A condição mesma dessa mobilização e dessa apropriação da língua é, para o locutor, a necessidade de referir pelo discurso, e, para o outro, a possibilidade de co-referir identicamente, no consenso pragmático que faz de cada locutor um co-locutor. A referência é parte integrante da enunciação.

(BENVENISTE, [1970]2006, p.84)

São estabelecidas, então, a nosso ver, as bases para que se possa falar da referência, como parte integrante da enunciação. Fica claro, aqui, que a referência não é "externa", pois integra o sistema da língua, em seu funcionamento. E, fazendo parte de seu sistema em funcionamento, pela necessidade de referir e de incluir o outro, circunscreve-se à realidade do discurso.

Dizer que a referência se dá na enunciação é dizer, então, que depende das coordenadas do locutor e da interlocução; e isso se relaciona com um fundamento essencial do processo de referência, que diz respeito ao fato de que somente podemos identificar um referente se identificarmos também a adequação da proposta do apontamento. Ou seja, a relação eu-tu não se reduz à questão formal, mas implica em importantes relações de sentido.

\subsection{Sentido e referência}

Para aprofundar a reflexão sobre essas relações de sentido e referência, e especificar melhor as condições de enunciação, uma importante distinção se faz necessária: a da "língua como semiótica" e a da "língua como semântica". A primeira característica da semiótica é apresentada no trecho a seguir.

Em semiologia, o que o signo significa não dá para ser definido. Para que um signo exista, é suficiente e necessário que ele seja aceito e que se relacione de uma maneira ou de outra com os demais signos (...) tudo que é do domínio do semiótico tem por critério necessário e suficiente que se possa identificá-lo no interior e no uso da língua. Cada signo entra numa rede de relações e oposições com os outros signos que o definem, que o delimitam no interior da língua. Quem diz "semiótico" diz "intralinguístico". (BENVENISTE, [1966]2006, p.227-228)

Para o autor, então, o semiótico não se ocupa da relação do signo com as coisas e, portanto, também não da relação entre a língua e o mundo.

A segunda característica está relacionada ao fato de que "o signo tem sempre e somente valor genérico e conceptual. Ele não admite significado particular" e, assim, as situações em que podem ocorrer são apenas virtuais. Por último, Benveniste [1966](2006) descreve as oposições semióticas como binárias, pois se dispõem em relações sempre paradigmáticas.

Em oposição a essa caracterização, toda dedicada ao signo, Benveniste se questiona, então, sobre "a frase": 
Qual a sua função comunicativa na língua? Afinal, é assim que nos comunicamos: por frases, mesmo que truncadas, embrionárias, incompletas, mas sempre por frases. Esta aí, em nossa análise, um ponto crucial. Contrariamente à ideia de que a frase possa constituir um signo no sentido saussuriano, ou que se possa por simples adição ou extensão do signo passar à proposição e depois aos diversos tipos de construções sintáticas, pensamos que o signo e a frase são dois mundos distintos e que exigem descrições distintas. (BENVENISTE, [1966]2006, p.228-229)

E, assim, muito mais do que sugerir uma reformulação do conceito de frase ${ }^{6}$, Benveniste propõe que se considerem dois domínios do sentido e da forma, um para o semiótico, outro para o que o autor denomina como semântico. Salienta, contudo, que, ainda que dotados de estatutos diferentes, os mesmos elementos se encontram numa e noutra parte. Para o autor, ainda, tratam-se de duas modalidades da função linguística: a de significar, para a semiótica, e a de comunicar, para a semântica.

A semântica está, então, no domínio da língua em ação. E a referência, além de integrar este domínio, depende totalmente de suas condições, desempenhando, ao mesmo tempo, um importante papel também para o sentido, conforme endossa o autor:

Coloquemos como princípio que o sentido de uma frase é outra coisa diferente do sentido das palavras que a compõem. O sentido de uma frase é sua ideia, o sentido de uma palavra é seu emprego (sempre na acepção semântica). A partir da ideia, a cada vez particular, o locutor agencia palavras que neste emprego tem um "sentido" particular. Além disso, é necessário introduzir aqui um termo a que foi desnecessário apelar na análise semiótica: aquele do "referente", independente do sentido, e que é o objeto particular a que a palavra corresponde no caso concreto da circunstância ou do uso. Ainda que se compreenda o sentido individual das palavras, pode-se muito bem, fora da circunstância, não compreender o sentido que resulta da junção das palavras; esta é uma experiência corrente, que mostra ser a noção de referência essencial. (BENVENISTE, [1966]2006, p.231)

Benveniste distingue, então, entre o sentido das palavras, que está relacionado ao seu emprego, e o sentido da frase, que é a ideia. Contudo, para se chegar ao sentido da "junção de palavras", que é como o autor se refere, aqui, à frase, é preciso entender a circunstância em que tal frase é dita, para que se identifique, também, o referente. Em outras palavras, o que garante a atribuição de sentido a um enunciado, além da compreensão do sentido lexical, é a compreensão das condições de enunciação - o que inclui, primordialmente, a referência.

Podemos dizer, então, que, do âmbito lexical às condições de enunciação, o sentido emerge na interdependência entre o semiótico e o semântico.

E, neste ponto, resgatamos um raciocínio alinhavado anteriormente sobre a designação, neste artigo, pois o pressuposto da interdependência entre o semiótico e o semântico dá suporte e explica melhor a questão. Se, de um lado, a designação está ligada à escolha lexical - e, dissemos, aqui, de maneira mais ampla, está

${ }^{6}$ Conforme Flores et. al (2008), “Às vezes, Benveniste utiliza o termo frase em um sentido equivalente ao do termo enunciado". De fato, nota-se, aqui, que o sentido de "frase", para Benveniste, assume um lugar de enunciado, pois não se trata mais de uma estrutura de palavras organizadas, na ordem da sintaxe, mas, sim, de algo que é dito na enunciação. É da ordem da língua em funcionamento, portanto, e não apenas da língua enquanto sistema. 
ligada à escolha de signos - a referência é a ancoragem, na realidade do discurso, que permite estabelecer o sentido dessa escolha.

O autor destaca também o aspecto imprevisível e sempre novo de cada frase, a cada enunciação, cujo sentido, pode, no entanto, ser fixado para cada situação, dependendo do conhecimento dos laços referenciais que a determinam:

Se o "sentido" da frase é a ideia que ela exprime, a "referência" da frase é o estado de coisas que a provoca, a situação de discurso ou de fato a que ela se reporta e que nós não podemos jamais prever ou fixar. Na maior parte dos casos, a situação é condição única, cujo conhecimento nada pode suprir. (BENVENISTE, [1966]2006, p.231)

A frase é "cada vez sempre um acontecimento diferente; ela não existe senão no instante em que é proferida e se apaga neste instante; é um acontecimento que desaparece" (BENVENISTE, [1966]2006, p.231) e, de tão fugaz, não pode "comportar emprego". E assim, retornamos à afirmação, no texto de 1970, mencionado anteriormente, sobre o emprego das formas ser muito diferente do emprego da língua: enquanto em um o inventário de elementos e combinações tende a ser limitado, no outro, na língua em funcionamento, ele é sempre novo, diferente e imprevisível.

Outro ponto a reforçar sobre o trecho anterior é o fato de que esse "estado de coisas" não se trata de um estado de coisas do mundo, cujas coordenadas são dadas pela referência, mas da percepção de estados de coisas que somente é acessível pela língua. Como explicamos anteriormente, para Benveniste - e para nossa pesquisa - a realidade do mundo é sempre aquela que é construída na língua e pela língua.

Por fim, das palavras do autor: "a situação de discurso ou de fato a que ela se reporta e que nós não podemos jamais prever ou fixar", ressaltamos a característica movediça da referência, que é também condição que possibilita que cada indivíduo ressignifique e reoriente a sua visão do mundo, a cada nova instância do discurso.

\section{CONSIDERAÇÕES FINAIS}

Confirmamos, inicialmente, neste artigo, que a redefinição do signo linguístico, conforme proposta por Benveniste, reformula a própria teoria dos signos saussuriana e permite incluir a referência, pois que é reestabelecida a relação do signo com o objeto.

E, mais do que isso, a redefinição da noção de arbitrariedade, de universal e de contingente, condiz com a nossa visão de que não há uma verdade a ser revelada no mundo pelo modo como apontamos para os objetos, mas que os objetos a que nos referimos são construtos, fruto dos conceitos que os falantes formulam sobre eles, na língua e pela língua.

Sob o ponto de vista que pretendemos construir e com base nos pressupostos enunciativos, conforme descritos neste artigo, a relação das palavras com o mundo não se trata de uma visão cartográfica da realidade, em que se pressupõe a autonomia do saber e a língua como um meio transparente de codificação do 
pensamento sobre objetos previamente discretizados. Isto é, a língua não é um espelho, que reflete os objetos "tais quais" estão no mundo; a língua é um sistema que permite que os falantes formulem e expressem suas visões de mundo. Assim, a referência não se constitui num apontamento para objetos do mundo constituídos a priori, mas depende de - e ao mesmo tempo contribui para - uma construção de sentido que se dá na interlocução.

Não é nossa preocupação a verificação de se o que falamos corresponde a uma verdade no mundo. Nesta abordagem, o saber se constitui na língua e não pode ser visto separadamente do homem que fala. Portanto, defendemos, aqui, que a relação das palavras com as coisas é o processo pelo qual os falantes se referem ao mundo na língua e pela língua, numa realidade que se constitui no discurso.

Também apresentamos, neste artigo, as principais características do processo de referência, conforme pressupostos enunciativos, que sumarizamos, a seguir: 1) a (inter)subjetividade, que marca o centro de coordenadas da realidade do discurso e a relação com o outro, permitindo aos locutores a se propor como sujeitos; 2) o traço da ostensão, em apontar para os objetos da realidade do discurso, também a partir da marca de pessoa; 3) a relação com o sentido: a referência é o estado de coisas que o determina; e, finalmente, 4) a sua relação com a enunciação: é nela que se realiza e, ao mesmo tempo, a ela fornece condições para a interpretação dos sentidos. Isso implica dizer, também, que a realidade para a qual apontamos, na referência, é a realidade do discurso, e não uma realidade do mundo.

E, finalmente, identificamos as condições de enunciação como o que possibilita que a referência assim funcione. A primeira condição é a situação que é instalada quando o locutor se propõe como sujeito e se torna o centro de referência. A segunda condição é a necessidade do locutor de referir o mundo, associada à subjetividade e intrínseca à própria linguagem. Como terceira condição, está a intersubjetividade que é instalada pela compulsória convocação do outro, na possibilidade de co-referir.

\section{REFERENCIAS}

APOTHÉLOZ, D. Référer sans expression référentielle : gestion de la référence et opérations de reformulation dans des séquences métalinguistiques produites dans une tâche de rédaction conversationnelle. In: Enikö N. (ed) Pragmatics in 2000: selected papers from the 7th International Pragmatics Conference, Vol. 2. Antwerp: International Pragmatics Association, 2001, p. 30-38.

BENVENISTE, E. A natureza do signo linguístico. In Problemas de Linguística Geral, I. Campinas: Pontes, [1939] 2005.

BENVENISTE, E. A natureza dos pronomes pessoais. In Problemas de Linguística Geral, I. Campinas: Pontes, [1956] 2005.

BENVENISTE, E. Da subjetividade na linguagem. In Problemas de Linguística Geral, I. Campinas: Pontes, [1958] 2005 
BENVENISTE, E. As relações de tempo no verbo francês. In: Problemas de linguistica geral, I. Campinas: Pontes, [1959] 2005.

BENVENISTE, E. A linguagem e a experiência humana. In: Problemas de Linguística Geral II. Campinas: Pontes, [1965] 2006

BENVENISTE, E. A forma e o sentido na linguagem. In: Problemas de Linguística Geral II. Campinas: Pontes, [1966] 2006.

BENVENISTE, E. O aparelho formal da enunciação. In: Problemas de Linguística Geral II. Campinas: Pontes, [1970] 2006.

BOAS, F. Introduction to Handbook on American Indian Languages. Lincoln: University of Nebraska Press, 1966.

BOUQUET, S. Introdução à leitura de Saussure. São Paulo: Cultrix, 2000.

CIULLA, A. Os processos de referência e suas funções discursivas: o universo literário dos contos. 201p. Tese (Doutorado em Linguística). Universidade Federal do Ceará, Fortaleza, 2008.

DE MAURO, T. Cours de linguistique générale: édition critique préparée par Tullio de Mauro. Paris: Payot, 1976.

ENGLER, R. Théorie et critique d'un príncipe saussurien: l'arbitraire du signe. Cahiers Ferdinand de Saussure, Genebra, Librairie E. Droz, n.19, p. 5-66, 1962.

FILLMORE, C. Lectures on deixis. Berkeley: University of California, 1971.

FILLMORE, C. Lectures on deixis. California: CSLI Publications, 1977.

FLORES, V.; BARBISAN, L.; FINATTO, M.J.; TEIXEIRA, M. Dicionário de Linguística da Enunciação. São Paulo: Contexto, 2008.

FLORES, V. Introdução à teoria enunciativa de Benveniste. São Paulo: Parábola, 2013.

FLORES, V. O que há para ultrapassar na noção saussuriana de signo? De Saussure a Benveniste. Revista Gragoatá, Niterói, v. 22, n.44, p. 1005-1026, 2017.

GADET, F. Saussure: une science de la langue. Paris: Presses Universitaires de France, 1997.

HUMBOLDT, W. Über die Verschiedenheit des menschlichen Sprachbaues und ihren Einfluss auf die geistige Entwickelung des Menschengeschlechts. Berlin: Dümmlers Verlag, 1836. Disponível em: https://archive.org/stream/berdieverschied00humbgoog\#page/n17/mode/2up

JAKOBSON, R. El signo y el sistema de la lengua: una reafirmación de la doctrina de Saussure. In: . Arte verbal, signo verbal, tempo verbal. México: Fondo de Cultura Económica, 1992.

LAHUD, M. A propósito da noção de dêixis. São Paulo: Ática, 1979.

LEVINSON, S. C. Pragmatics. Cambridge: Cambridge University Press, 1983. 
LYONS, John. Semantics. London: Cambridge University Press. 2.v., 1977.

LYONS, John. Deixis and subjectivity: loquor, ergo sum? In: JARVELLA, R.J.; KLEIN, W. (eds.) Speech, place and action: studies in deixis and related topics. New York: John Wiley and Sons, 1982, p. 101-23.

MILNER, J-C. Réflexions sur l'arbitraire du signe. Ornicar, v. 5, p. 73-85, 1975.

MONDADA, L. ; DUBOIS, D. Construction des objets de discours et catégorisation: une approche des processus de référenciation. In: TRANEL (Travaux Neuchâtelois de Linquistique), n.23, 1995, p.273-302. Tradução para o português: Construção dos objetos do discurso e categorização: uma abordagem dos processos de referenciação. In: CAVALCANTE, M. M.; RODRIGUES, B. B.; CIULLA, A. (orgs.) Referenciação. São Paulo: Contexto, 2003, p. 17-52.

NORMAND, C. L'arbitraire du signe comme phénomène de déplacement. Dialectique, v. 1, p. 109$126,1973$.

SAUSSURE, F. Curso de Linguística Geral. Trad. Antônio Chelini, José Paulo Paes, Isidoro Blikstein Cultrix, São Paulo: 1975.

SLOBIN, D.I. From "thought and language" to "thinking for speaking". In: J.J. GUMPERZ e S.C. LEVINSON (eds.) Rethinking linguistic relativity. Cambridge: Cambridge University Press, 1996, p.70-96.

WHORF, B.L. Language, thought and reality. Cambridge: Technology Press of Massachussets Institute of Technology, 1956. Disponível em https://openlibrary.org/books/OL6197196M/ LANGUAGE THOUGHT and REALITY 